\title{
Ultrasound in pediatric surgery; intraoperative applications of the growing technology
}

\author{
Osama Bawazir ${ }^{1,2^{*}}$ (D) and Omemh Abdullah Bawazeer ${ }^{3}$
}

\begin{abstract}
Background: Ultrasonography is increasingly used in pediatric surgery. Intraoperatively, ultrasonography can be used to confirm the preoperative diagnosis, guide the surgical approach, and enhance decision-making. We aimed to report our experience with intraoperative ultrasonography in different neonatal and pediatric procedures. So, a retrospective study was designed. It included all pediatric patients who had intraoperative ultrasound between January 2018 and October 2020 in a single center.

Results: We used intraoperative ultrasonography in 208 pediatric patients for various types of surgery. The authors compared ultrasound-guided central line insertion $(n=139)$ to the landmark method $(n=153)$. The number of trials was significantly lower in the ultrasound-guided method $(P<0.001)$. Conversion to cut-down was significantly lower with the ultrasound-guided technique (4 (2.8\%) vs. $13(8.5 \%) ; \mathrm{P}=0.047)$ and insertion-related complications were lower with ultrasound (0 vs $13(8.5 \%) ; \mathrm{P}<0.001)$. We used ultrasound-guided sclerotherapy for cystic hygroma in 15 patients. Nine patients had successful treatment with a single injection (60\%).

Conclusion: The application of intraoperative ultrasound in pediatric patients is increasing in our institution. The technique is safe and could effectively reduce central line insertion complications and enhance cystic hygroma sclerotherapy's success with a single injection. Ultrasonography should be an essential part of residents' and fellows' training in pediatric surgery.
\end{abstract}

Keywords: Intraoperative ultrasonography, Pediatric surgery training, Central line insertion, Cystic hygroma

\section{Background}

The use of intraoperative ultrasonography (IOUS) in pediatric surgery is growing. There are several benefits of ultrasonography in this field, yet its incorporation into daily practice is slow [1]. Ultrasonography produces realtime imaging in different clinical settings, including bedsides, outpatient clinics, and operating rooms.

It is essential to understand the basics of ultrasonographic physics for proper image interpretation and

\footnotetext{
*Correspondence: obawazir@yahoo.com; Oabawazir@uqu.edu.sa

'Department of Surgery, Faculty of Medicine, Umm Al-Qura University,

21955, Makkah P.O. Box 715, Saudi Arabia

${ }^{2}$ Department of Surgery, King Faisal Specialist Hospital \& Research Centre,

P.O.box 40047 Jeddah21499Kingdom of Saudi Arabia

Full list of author information is available at the end of the article
}

diagnosis. The ultrasound's transducer emits and receives sound waves [2]. The most frequently used ultrasonographic mode is the two-dimensional B-mode. The images produced by this mode are black and white and can be modified by changing the probe's shape and size and the waves' frequencies [3].

Sound waves are reflected more from the solid medial because of their dense particles [4]. Solid tissues are echogenic (white), and fibrous tissues appear white with shadows, and bones appear white without shadows. Fluids are anechoic (black), and soft tissues appear gray [5]. Air reflects sound waves and appears hyperechoic with while lines that prevent visualization of deeper structures [6]. These white lines are the reverberation
Springer Open (c) The Author(s). 2021 Open Access This article is licensed under a Creative Commons Attribution 4.0 International License, which permits use, sharing, adaptation, distribution and reproduction in any medium or format, as long as you give appropriate credit to the original author(s) and the source, provide a link to the Creative Commons licence, and indicate if changes were made. The images or other third party material in this article are included in the article's Creative Commons licence, unless indicated otherwise in a credit line to the material. If material is not included in the article's Creative Commons licence and your intended use is not permitted by statutory regulation or exceeds the permitted use, you will need to obtain permission directly from the copyright holder. To view a copy of this licence, visit http://creativecommons.org/licenses/by/4.0/. 
artifacts, and they are very useful for the diagnosis of intraperitoneal free air.

Intraoperatively, ultrasonography can be used to confirm the preoperative diagnosis, guide the surgical approach, and enhance decision-making. Several ultrasound-guided methods have been adopted, such as hepatic lesion mapping during resection. Ultrasonography has proven safety, and proper ultrasound use in the operating room could reduce the intervention time and improve patient outcomes. This technology has changed the operative management of central venous catheter insertion by reducing the complication rate and the total number of cannulation trials [7].

The use of ultrasonography has been expanded to include trauma, endocrine, breast, and vascular surgery [8]. In pediatric surgery, ultrasonography can be used to diagnose pyloric stenosis and acute appendicitis and in several interventions such as central line $[9,10]$ and port-a-cath insertion [11].

The increasing role of ultrasound in pediatric surgery motivated us to perform this study to evaluate the role of intraoperative ultrasonography and report our experience with it in different procedures for children and neonates.

\section{Methods}

\section{Design and patients}

This retrospective study included 208 pediatric patients who had intraoperative ultrasound between January 2018 and October 2020 in a single center. The Institutional Review Board approved the study, and the need for the patients' consent to participate in the research was waived.

\section{Data collected}

We highlighted some of the procedures in which intraoperative ultrasonography was used.

We extracted the data required for this study from the electronic and paper charts. The obtained data included age, the indication of the procedure, and the operative times. Study endpoints were the success of using the ultrasound-guided approach, conversion to open approach, and postoperative complications.

\section{Ultrasonography techniques}

We used probes with different frequencies depending on the target tissues. Tissue penetration is higher with lowfrequency probes, while the penetration is lower with high-frequency probes, but they have better resolution. Therefore, we used low-frequency probes $(2-5 \mathrm{MHz})$ to evaluate the deep structures and in obese patients and high-frequency probes $(6-13 \mathrm{MHz})$ for superficial structures.
We washed the scan head with alcohol before use and placed sterile gel into a long sterile plastic sleeve. We introduced the transducer wire over this plastic sleeve and secured it with rubber bands povidone-iodine or sterile gel is used as the coupling agent.

\section{Statistical analysis}

We described the continuous data as mean and standard deviation and categorical data as number and percent. Continuous data were compared using the $t$ test and categorical data with the Chi-square or Fisher exact test when appropriate. SPSS version 26 (IBM Corp., Armonk, NY, USA) was used to perform the descriptive statistics.

\section{Results}

Procedures

We used intra-operative ultrasonography during the following procedures: sclerotherapy for cystic hygroma (n $=15)$, tunneled vascular access $(\mathrm{n}=139)$, liver mass excision $(\mathrm{n}=7)$, drain insertion ( $\mathrm{n}=3$ ), lymph node biopsy $(\mathrm{n}=5)$, check the position of the double J-stent during pyloroplasty $(n=3)$, check the position of nasogastric tube $(\mathrm{n}=8)$, rectus sheet block $(\mathrm{n}=15)$, lymph node mapping for biopsy $(\mathrm{n}=8)$, and intraoperative assessment of the volume status and echocardiography $(\mathrm{n}=$ 5).

\section{Ultrasound and cystic hygroma}

We used ultrasound-guided sclerotherapy for cystic hygroma in 15 patients. The most common site was the neck. Nine patients had successful treatment (complete resolution) with a single injection $(60 \%)$ (Table 1$)$.

\section{Ultrasound-guided central line insertion}

Ultrasound-guided central line insertion was performed in 139 patients (Fig. 1). We compared these patients to 153 patients who had line insertion through the landmark method. There were no differences in the baseline data between both approaches. The number of trials was

Table 1 Cystic hygroma patients

\begin{tabular}{ll}
\hline & (n = 15) \\
\hline Male & $8(53.4 \%)$ \\
Site & $5.7 \pm 3.83$ \\
Head and neck & \\
Trunk & $10(66.6 \%)$ \\
Limbs & $3(20.0 \%)$ \\
Number of injections & $2(13.4 \%)$ \\
Single injection & \\
Two injection & $9(60 \%)$ \\
Three or more injection & $4(26.6 \%)$ \\
\hline
\end{tabular}




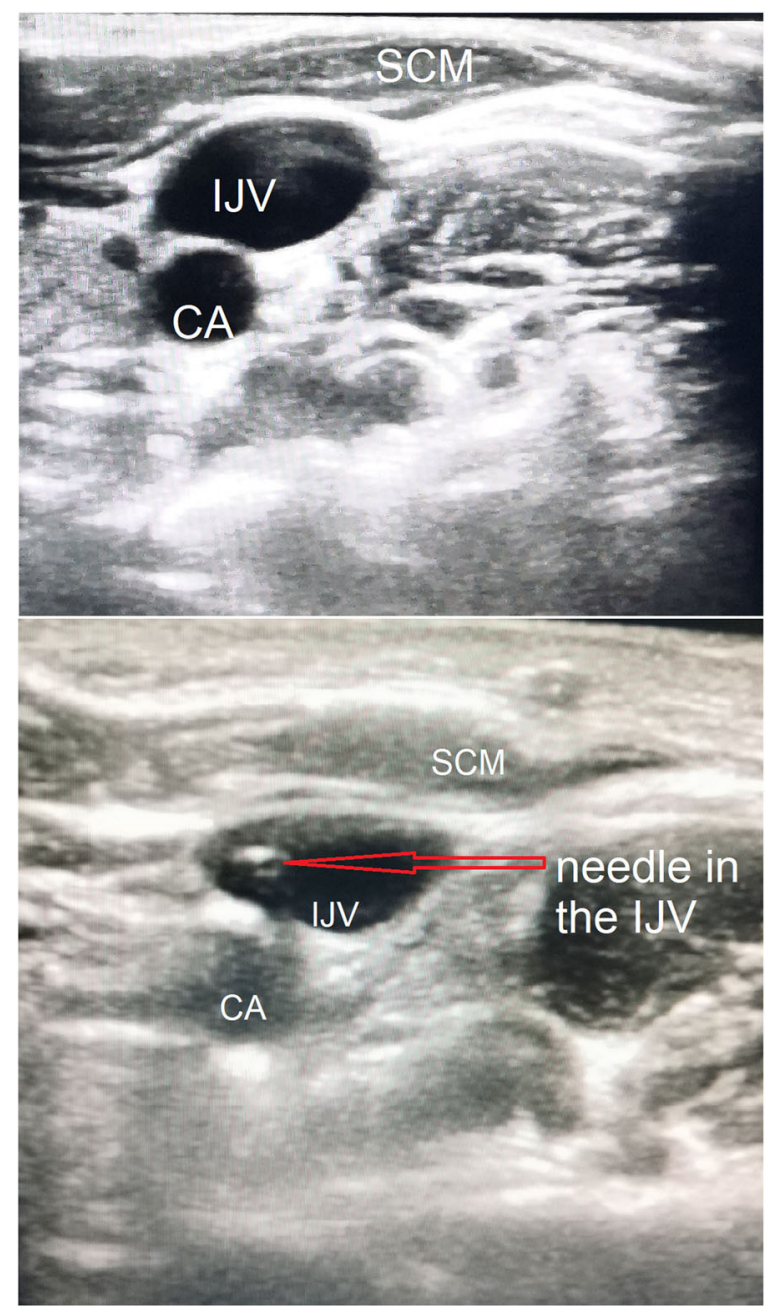

Fig. 1 Ultrasound-guided central line insertion (CA, carotid artery; IJV, internal jugular vein; SCM, sternocleidomastoid muscle). Arrow shows the needle in the IJV

significantly lower in the ultrasound-guided method (Table 2).

Conversion to cut-down was significantly lower with the ultrasound-guided technique $(4(2.8 \%)$ vs. $13(8.5 \%)$; $P=0.047)$ and insertion-related complications were lower with ultrasound ( 0 vs $13(8.5 \%) ; P<0.001)$. There were no differences in other complications, including bleeding, pneumothorax, arterial injury, and infection between groups (Table 3 ).

\section{Discussion}

Improving the surgical vision and enhancing the diagnosis will improve the surgical outcomes. Ultrasonography is a widespread technique with proven safety that is already in use in several medical specialties. This technique's application has expanded to include intraoperative use in thyroid surgery [12], hepatobiliary surgery [13], and neurosurgery [14].

The technique was introduced to pediatric surgery and became of utmost importance in several procedures. Intraoperative ultrasonography can be used during liver tumor resection. It effectively shows the surrounding vessels and tumor margins, and depth. Its imaging accuracy was comparable to the preoperative computed tomography scan. Additionally, intraoperative ultrasonography provides real-time feedback during surgery, and it can be repeated several times to provide continuous feedback to the surgeon. This application's potential benefits are reducing bleeding, operative time, and performing complete surgical resection. In a previous study, intraoperative ultrasonography in pediatric surgery decreased the rate of positive surgical margins [15].

Another application of ultrasonography in pediatric surgery is central line insertion. Traditionally, the central line is inserted through the landmark method. This method may increase the number of trials before successful insertion and the insertion-related complications [16]. Like other studies, we reported fewer puncture trials in the ultrasound-guided method and lower insertion-related complications, such as neck hematoma and carotid artery puncture [7]. The efficacy and safety of ultrasound-guided vascular puncture have been demonstrated in several studies [17]. Ultrasound-guided insertion demonstrated a higher success rate than the landmark method in a multicenter study [18]. The main barrier to the generalization of ultrasound-guided

Table 2 Preoperative and operative data for patients who had central line insertion with the landmark versus ultrasound-guided method

\begin{tabular}{|c|c|c|c|}
\hline Variable & Anatomic landmark method $(n=153)$ & Ultrasound-guidance method $(n=139)$ & $P$ value \\
\hline Age (year) & $5.17 \pm 3.49$ & $4.62 \pm 3.14$ & 0.16 \\
\hline Sex (female/male) & $60 / 93$ & $59 / 80$ & 0.58 \\
\hline Operative time (minutes) & $46 \pm 46.3$ & $40.3 \pm 16.3$ & 0.17 \\
\hline Number of trials & $2.8 \pm 1.9$ & $1.9 \pm 1.1$ & $>0.001$ \\
\hline \multicolumn{4}{|l|}{ Indications } \\
\hline Chemotherapy & (128) 83.7\% & (117) 84.2\% & 0.91 \\
\hline Other & (25) $16.3 \%$ & (22) $15.8 \%$ & \\
\hline
\end{tabular}


Table 3 Procedure complications.

\begin{tabular}{llll}
\hline Variable & Anatomic landmark method $(\boldsymbol{n}=\mathbf{1 5 3})$ & Ultrasound-guidance method $(\boldsymbol{n}=\mathbf{1 3 9})$ & $\boldsymbol{P}$ value \\
\hline Non & $(116) 75.8 \%$ & $(115) 82.7 \%$ & 0.15 \\
Bleeding * & $(4) 2.6 \%$ & 0 & 0.12 \\
Pneumothorax (chest tube inserted) & $(3) 2.0 \%$ & 0 & 0.25 \\
Arterial puncture & $(5) 3.3 \%$ & 0 & 0.06 \\
Arterial insertion & $(1) 0.65 \%$ & 0 & $>0.99$ \\
Conversion to cut down & $(13) 8.5 \%$ & (4) $2.8 \%$ & $(18) 13.0 \%$ \\
Infection & $(20) 13.1 \%$ & (4) $2.9 \%$ & 0.047 \\
Malfunction & (5) $3.3 \%$ & 0 & $>0.98$ \\
Insertion related complication & (13) $8.5 \%$ & & $<0.001$ \\
\hline
\end{tabular}

*Bleeding requires blood transfusion or chest tube insertion

vascular puncture is the lack of formal ultrasound training, and several programs are still considering this technology nonessential [19].

Although several studies have demonstrated the potential advantage of ultrasound use in pediatrics, several limitations exist. Several centers around the globe had initiated ultrasonography training programs for pediatric surgery residents and fellows. These training programs did not replace the conventional radiological methods with ultrasonography but used them to enhance each other's success.

Ultrasonography needs a learning experience and repeated use to improve the learning curve. Additionally, probes suitable for neonates and infants are not widely available. Currently, small and portable ultrasonography devices with high resolution are available for use in pediatric patients. These small machines were incorporated into pediatric patients' daily care, and some centers reported an improvement of the surgical outcomes with this technology [20].

Another drawback of ultrasonographic use in pediatric surgery is the medicolegal aspect. Pediatric surgeons are not well-trained to perform a comprehensive radiological assessment as the trained radiologists. However, ultrasonography is used as an adjunct to the physical examination, and radiological consultation is always available for complex cases. Additionally, the training can be enhanced with hands-on experience on simulators and manikins. The training programs should familiarize the fellow with the components of ultrasound machines and include an introduction to ultrasound physics in the curriculum. The training experience can be enhanced by comparing the preoperative $\mathrm{CT}$ images to the intraoperative ultrasound images.

Ultrasonography is not a screening tool only; it has proven interventional and therapeutic benefits [21]. The use of ultrasonography during surgical interventions decreases the procedure's invasiveness, time, and complications [3]. The use of ultrasound may decrease the need for further diagnostic work-up. Real-time imaging provided intraoperatively may lead to early detection and prevention of several complications. The transition to this technology requires a national initiative that makes ultrasound machines readily available for all pediatric surgeons, moreover, incorporates a formal ultrasound training curriculum in many surgical residencies [22]. The technology is cost-effective compared to other imaging modalities such as intraoperative MRI. Therefore, intraoperative ultrasound is the optimal imaging tool that should be adopted worldwide [23].

\section{Study limitations}

The study has several limitations, including the retrospective nature of the study and the limited number of most of the applications other than central venous catheter $(\mathrm{CVC})$ insertion and the cystic hygroma.

\section{Conclusion}

The application of intraoperative ultrasound in pediatric patients is increasing in our institution. The technique is safe and could effectively reduce central line insertion complications and enhance cystic hygroma sclerotherapy's success with a single injection. Ultrasonography should be an essential part of residents' and fellows' training in pediatric surgery.

\section{Abbreviations}

IOUS: Intraoperative ultrasonography; CVC: Central venous catheter

\section{Acknowledgements}

I would like to express my deep gratitude to Miss Razan Bawazir for here valuable support on photo editing in this article.

\section{Authors' contributions}

$O B$ and $O A B$ made the study design. $O A B$ did extensive literature review, analyzed, and interpreted the patient data regarding the intraoperative ultrasound for children. $\mathrm{OAB}$ and $\mathrm{OB}$ performed the data collection and was a major contributor in writing the manuscript. $O A B$ and $O B$ did the final revision and correction of the manuscript. Both authors contributed to the conception or design of the work and/or the acquisition, analysis, and interpretation of data. Drafts were revised critically for important intellectual content and the final version approved by all. Both agree to be accountable 
for all aspects of the work. The authors read and approved the fina manuscript.

\section{Funding}

None

\section{Availability of data and materials}

The datasets generated and/or analyzed during the current study are not publicly available due [patient confidentiality policy in our institution] but are available from the corresponding author on reasonable request.

\section{Declarations}

\section{Ethics approval and consent to participate}

All procedures performed in studies involving human participants were in accordance with the ethical standards of the institutional and/or national research committee and with the 1964 Helsinki Declaration and its later amendments or comparable ethical standards. The study was approved by the Institutional Biomedical Ethical Committee, Faculty of Medicine, Um Al Qura University (Institutional Review Number iHAPQ-02-K-012-2021-02-551).

\section{Consent for publication}

Verbal consent was obtained from the parents of all patients included in the study.

\section{Competing interests}

Author OB declares that he has no conflict of interest.

\section{Author details}

'Department of Surgery, Faculty of Medicine, Umm Al-Qura University, 21955, Makkah P.O. Box 715, Saudi Arabia. ²Department of Surgery, King Faisal Specialist Hospital \& Research Centre, P.O.box 40047 Jeddah21499Kingdom of Saudi Arabia. ${ }^{3}$ College of Applied Science, Department of medical physics, Umm Al-Qura University, Makkah, Saudi Arabia.

Received: 10 February 2021 Accepted: 25 May 2021 Published online: 16 August 2021

\section{References}

1. Bonasso PC, Dassinger MS, Wyrick DL, Gurien LA, Burford JM, Smith SD. Review of bedside surgeon-performed ultrasound in pediatric patients. J Pediatr Surg. 2018Nov;53(11):2279-2289. doi: https://doi.org/10.1016/j. jpedsurg.2018.04.040. Epub 2018 May 8.

2. Hangiandreou NJ. AAPM/RSNA physics tutorial for residents. Topics in US: Bmode US: basic concepts and new technology. Radiographics. 2003 JulAug;23(4):1019-33. https://doi.org/10.1148/rg.234035034.

3. Abu-Zidan FM. Basic ultrasound physics, instrumentation, and knobology. In: Zago M, editor. Essential US for trauma: E-FAST. First ed. Milan: SpringerVerlag Italia; 2014. p. 1-13. https://doi.org/10.1007/978-88-470-52 74-1_1.

4. Rose JS. Ultrasound physics and knobology. In: Simon BC, Snoey ER, editors. Ultrasound in emergency and ambulatory medicine. St Louis: Mosby-Year book Inc; 1997. p. 10-38.

5. Rose JS, Bair AE. Fundamentals of ultrasound. In: Cosby KS, Kendall JL, editors. Practical guide to emergency ultrasound. PA: Lippincott Willaims and Wilkins; 2006. p. 27-41.

6. Schuler A. Image artifacts and pitfalls. In: Mathis G, editor. Chest sonography. Second edition. New York: Springer; 2008. p. 175-182, doi: https://doi.org/10.1007/978-3-540-72428-5_8

7. Hind D, Calvert N, McWilliams R, Davidson A, Paisley S, Beverley C, et al. Ultrasonic locating devices for central venous cannulation: meta-analysis. BMJ. 2003Aug 16;327((7411)):361-0. https://doi.org/10.1136/bmj.327.7411.3 61.

8. Rozycki GS. Surgeon-performed ultrasound: its use in clinical practice. Ann Surg. 1998Jul;228((1)):16-28. https://doi.org/10.1097/00000658-19980700000004.

9. Boneti C, McVay MR, Kokoska ER, Jackson RJ, Smith SD. Ultrasound as a diagnostic tool used by surgeons in pyloric stenosis. J Pediatr Surg. 2008Jan; 43(1):87-91; discussion 91. doi:https://doi.org/10.1016/j.jpedsurg.2007.09.027.
10. Criss CN, Gadepalli SK, Matusko N, Jarboe MD. Ultrasound guidance improves safety and efficiency of central line placements. J Pediatr Surg. 2019Aug;54(8):1675-1679. doi: https://doi.org/10.1016/j.jpedsurg.2018.08.039. Epub 2018 Sep 13.

11. Bawazir O, Bawazir A. Ultrasound guidance for Port-A-Cath insertion in children; a comparative study. Int J Pediatr Adolescent Med. 2020. https:// doi.org/10.1016/j.ijpam.2020.08.002

12. Lew JI, Rodgers SE, Solorzano CC. Developments in the use of ultrasound for thyroid cancer. Curr Opin Oncol. 2010Jan;22((1)):11-6. https://doi.org/1 0.1097/CCO.0b013e3283337f16.

13. Marcal LP, Patnana M, Bhosale P, Bedi DG. Intraoperative abdominal ultrasound in oncologic imaging. World J Radiol. 2013Mar 28;5(3):51-60. https://doi.org/10.4329/wjr.v5.i3.51.

14. van Leyen K, Klötzsch C, Harrer JU. Brain tumor imaging with transcranial sonography: state of the art and review of the literature. Ultraschall Med. 2011 Dec;32(6):572-581. doi: https://doi.org/10.1055/s-0031-1273443. Epub 2011 Oct 27.

15. Stanescu AL, Kamps SE, Dick AAS, Parisi MT, Phillips GS. Intraoperative Doppler sonogram in pediatric liver transplants: a pictorial review of intraoperative and early postoperative complications. Pediatr Radiol. 2018Mar;48(3):401-410. doi: https://doi.org/10.1007/s00247-017-4053-0. Epub 2017 Dec 22. PMID: 29273893.

16. McGee DC, Gould MK. Preventing complications of central venous catheterization. N Engl J Med. 2003 Mar 20;348((12)):1123-33. https://doi. org/10.1056/NEJMra011883.

17. Lamperti M, Bodenhaum AR, Pittiruti AR, Blaivas M, Augoustides JG, Elbarbary, et al. International evidence-based recommendations on ultrasound-guided vascular access. Intensive Care Med. 2012;38(7):1105-17. https://doi.org/10.1007/s00134-012-2597-x.

18. Miller JW, Vu DN, Chai PJ, Kreutzer JH, John JB, Vener DF, Jacobs JP. Upper body central venous catheters in pediatric cardiac surgery. Paediatr Anaesth. 2013Nov;23(11):980-988. doi: https://doi.org/10.1111/pan.12261. Epub 2013 Sep 19.

19. Dassinger MS, Renaud EJ, Goldin A, Huang EY, Russell RT, Streck CJ, Tang X, Blakely ML. Use of real-time ultrasound during central venous catheter placement: results of an APSA survey. J Pediatr Surg. 2015Jul;50(7):11621167. doi: https://doi.org/10.1016/j.jpedsurg.2015.03.003. Epub 2015 Mar 13.

20. Flatman S, Kwok MMK, Magarey MJR. Introduction of surgeon-performed ultrasound to a head and neck clinic: indications, diagnostic adequacy and a new clinic model? ANZ J Surg. 2020May;90(5):861-866. doi: https://doi. org/10.1111/ans.15886. Epub 2020 Apr 30.

21. Krishnamurthy G, Keller MS. Vascular access in children. Cardiovasc Intervent Radiol. 2011Feb;34(1):14-24. doi: https://doi.org/10.1007/s00270-010-9865-3. Epub 2010 May 26.

22. Nassour I, Spalding MC, Hynan LS, Gardner AK, Williams BH. The surgeonperformed ultrasound: a curriculum to improve residents' basic ultrasound knowledge. J Surg Res. 2017Jun 1;213:51-59. doi: https://doi.org/10.1016/j. jss.2017.02.031. Epub 2017 Feb 27.

23. Perin A, Prada FU, Moraldo M, Schiappacasse A, Galbiati TF, Gambatesa E, d'Orio P, Riker NI, Basso C, Santoro M, Meling TR, Schaller K, DiMeco F. USim: a new device and app for case-specific, intraoperative ultrasound simulation and rehearsal in neurosurgery. A preliminary study. Oper Neurosurg (Hagerstown). 2018 May 1;14(5):572-578. doi: https://doi.org/10.1093/ons/ opx144.

\section{Publisher's Note}

Springer Nature remains neutral with regard to jurisdictional claims in published maps and institutional affiliations. 